\title{
Contextos educacionais e temas de estudos presentes em relatos de pesquisas em Educação Ambiental divulgados em periódicos nacionais
}

\section{Educational contexts and study themes present in research reports in Environmental Education published in national journals}

\section{Contextos educativos y temas de estudio presentes en los relatos de investigación en Educación Ambiental publicados en periódicos nacionales}

\author{
Dayane dos Santos Silva ${ }^{1}$ \\ Juliana Rink ${ }^{2}$
}

\begin{abstract}
Resumo
Este trabalho tem como objetivo analisar relatos de pesquisa publicados em periódicos nacionais, no campo da EA, no período de 2014-2018, em relação aos contextos educacionais e temas de estudo. Trata-se de uma pesquisa de "estado da arte" e envolveu a análise de 639 relatos de pesquisa publicados pelos periódicos Remea, Ambiente e Educação, RevBEA e PEA, selecionados no Portal de Periódicos Capes. Os quatro periódicos considerados são de acesso aberto e as publicações são, majoritariamente, em português. Os resultados apontam para predominância do contexto educacional escolar $(51,7 \%)$. Os relatos de pesquisas que possuem como tema de estudo concepções, representações, percepções sobre elementos ligados à temática ambiental representam $31 \%$ dos trabalhos. Ademais, espera-se contribuir para as discussões relativas à produção científica da EA brasileira, bem como os tipos e enfoques das pesquisas em EA privilegiados pelo campo.
\end{abstract}

Palavras-chave: Produção científica em Educação Ambiental. Periódicos. Estado da Arte.

\begin{abstract}
This study aims to analyze research reports published in national Environmental Educational journals, published between 2014-2018, discussing their educational contexts and study themes. This is a "state of the art" research and analyzed 639 research reports published by the periodicals Remea, Ambiente e Educação, RevBEA and PEA; present in the Portal de Periódicos Capes. All four journals are open access and the articles are mostly written in Portuguese. There is a predominance of research on the school educational context (51,7\%). Research whose theme of study is conceptions, representations, perceptions about elements related to the environmental theme represent $31 \%$. It is expected to contribute to discussions about the scientific production of Brazilian EE, and about types and approaches of research in EE privileged by the field.
\end{abstract}

Keywords: Scientific production in Environmental Educacion. Journals. State of the Art.

\section{Resumen}

Este estudio tiene como objetivo analizar informes de investigación publicados en revistas nacionales de Educación Ambiental, publicados entre 2014-2018, discutiendo sus contextos educativos y temas de estudio. Se trata de una investigación de "estado del arte" que implicó el análisis de 639 informes de investigación publicados por las revistas Remea, Ambiente e Educação, RevBEA y PEA; presente en el portal de revistas de la Capes. Todas las revistas son de acceso abierto y la mayoría de los artículos están escritos en portugués. Predomina la investigación sobre el contexto educativo escolar $(51,7 \%)$. Las investigaciones que tienen por objeto de estudio concepciones, representaciones, percepciones sobre elementos relacionados con la temática ambiental representan el $31 \%$ de los trabajos. Se espera que contribuya a las discusiones relacionadas con la producción científica de la EA brasileña, y sobre los tipos y enfoques de investigación en EA privilegiados por el campo.

\footnotetext{
${ }^{1}$ Doutora em Educação pela Unesp, Rio Claro/SP. E-mail: dayanedosssilva@gmail.com

${ }^{2}$ Doutora em Educação, Professora da Faculdade de Educação, Unicamp, Campinas/SP. E-mail: jurink@unicamp.br
} 
Palabras clave: Producción científica en educación ambiental. Periódicos. Estado del Arte. 1 Introdução

Com as discussões, a partir das décadas de 1960 e 1970, referentes às problemáticas ambientais, os debates sobre essa temática tornaram-se uma questão central em diversos espaços, nos contextos internacional e nacional, tendo como uma das suas principais preocupações a relação sociedade-natureza.

Nesse cenário de constituição do discurso ambiental, que associa a temática ambiental ao processo educativo, é que se constrói e delimita a produção científica em Educação Ambiental (EA). Para Sato e Santos (2003, p. 255), “(...) discutir os caminhos da pesquisa talvez seja uma forma interessante de corroborar com a (re)construção da EA". Assim, a possibilidade de se conhecer o cenário investigativo do contexto nacional em EA nos conduz, dentre outras coisas, a uma possível caracterização de sua constituição enquanto um campo de pesquisa.

A EA traz uma problemática - a questão ambiental - que é de suma importância e que vem sendo discutida há mais de cinco décadas (MEGID NETO, 2009). Para Megid Neto (2009) e Kawasaki e Carvalho (2009), é inegável que a EA já assume o estatuto de campo de conhecimento específico.

Embora possa ser identificada desde os anos 1980, a expansão da produção acadêmica brasileira em EA é recente e, conforme Carvalho et al. (2016), possui uma produção bibliográfica significativa, no âmbito quantitativo e em relação à diversidade temática, geográfica, metodológica e epistemológica.

É importante ressaltar que tal produção em EA tem sido divulgada em diferentes espaços, desde os programas de pós-graduação, a partir das teses e dissertações, e em eventos científicos regionais, nacionais e internacionais, tais como o Encontro Pesquisa em Educação Ambiental (EPEA) e o World Environmental Education Congress (Weec). Podemos considerar que, no Brasil, essa produção tem ganhado notoriedade com a divulgação em periódicos. Em 1996, foi lançado o primeiro periódico dedicado especificamente para a produção da EA, sob responsabilidade de pesquisadores do Programa de Pós-Graduação em Educação Ambiental da Universidade Federal do Rio Grande do Sul (Furg), Ambiente \& Educação: revista em Educação Ambiental. Carvalho (2015) assume a existência de periódicos nacionais voltados para divulgar pesquisas e ensaios no campo de pesquisa em EA.

No Brasil, a partir da expansão do campo de pesquisa em EA, nos diferentes espaços de divulgação científica, e da reconhecida importância de iniciativas de sistematização dessa produção, alguns estudos têm sido desenvolvidos no sentido de conhecer a pesquisa em EA nos meios de divulgação. Uma dessas iniciativas é o Projeto EArte - Projeto EArte ${ }^{3}$ (Estado da Arte da Pesquisa em Educação Ambiental no Brasil) (CARVALHO, 2009), que há mais de dez anos tem se dedicado a inventariar e sistematizar a pesquisa em EA sob a forma de dissertações e teses, realizando estudos descritivo-compreensivos e analíticos. Podemos citar o estudo de Nogueira (2016) sobre práticas interdisciplinares, e o de Dias (2012), sobre a dimensão valorativa da EA em pesquisas sobre formação continuada de professores.

Entretanto, há estudos sobre a produção científica em EA que se utilizam de outras fontes de dados, tais como a publicação veiculada em eventos. Podemos citar os trabalhos de Cavalari, Santana e Carvalho (2006) e Rink (2009) que analisaram trabalhos de edições do Encontro Pesquisa em Educação Ambiental (EPEA). Também, existem pesquisas que analisam a publicação veiculada por periódicos científicos, como os estudos de Santos e

\footnotetext{
${ }^{3}$ Maiores informações, acesse o sítio eletrônico do projeto: www.earte.net.
} 
Martins (2007), que investigou publicações em periódicos das áreas de Educação em Ciências, Educação e EA, de 1999 até 2006, e de Kreuz (2018), sobre a produção veiculada pela revista Brasileira de Educação Ambiental (2010-2016).

Segundo Packer (2011), a partir de 2009 os periódicos científicos são responsáveis por mais de um terço da produção científica brasileira. O autor cita que os periódicos nacionais, publicados e indexados online com acesso aberto da Scientific Eletronic Library Online (SciELO) alcançou média mensal de mais de 10 milhões de downloads de arquivos em 2010.

Assim, considerando a importância de esforços e iniciativas que buscam contribuir para um retrato da EA (CARVALHO, 2009), este estudo tem como objetivo analisar relatos de pesquisa publicados em periódicos nacionais no campo da EA, no período de 2014-2018, em relação aos contextos educacionais e temas de estudo.

\section{Delineamento Metodológico}

Trata-se de um estudo do tipo estado da arte, que possui caráter de revisão bibliográfica (MEGID NETO, 2009). De cunho inventariante e descritivo, conforme o autor, tais estudos investigam a produção em determinada área do conhecimento, implicando na identificação, seleção e classificação dos documentos conforme critérios estabelecidos, descrição, análise, avaliação do material e, por fim, identificação das tendências e lacunas da produção analisada.

A primeira etapa consistiu na determinação dos periódicos que seriam analisados, realizada a partir de uma busca no portal Qualis Periódicos - Plataforma Sucupira, da Coordenação de Aperfeiçoamento de Pessoal de Nível Superior (Capes). Esclarecemos que, neste trabalho, usamos a plataforma como local de busca dos periódicos, sem considerar a distinção conforme o Qualis, a qual é usada pela Capes com intuito de estratificar a produção dos programas de pós-graduação.

Dentro da plataforma, optamos pela classificação de periódicos no quadriênio 20132018, tendo em vista que o processo de seleção dos dados deste trabalho teve início no ano de 2018. Realizamos a busca pelo termo "Educação Ambiental", no título e/ou subtítulo da revista, o que retornou seis publicações. Para refinamento, assumimos como critérios: (a) o periódico estar ativo até o ano de 2018; (b) a disponibilização online, em formato eletrônico e acesso aberto (c) a vinculação da publicação com alguma universidade do país; (d) a explicitação e identificação da equipe editorial no sítio eletrônico oficial da revista. Esse processo resultou em quatro publicações: Revista de Pesquisa em Educação Ambiental $(\mathrm{PEA})^{4}$; Revista Brasileira de Educação Ambiental (RevBEA) ${ }^{5}$; Ambiente \& Educação: Revista de Educação Ambiental ${ }^{6}$; Revista Eletrônica do Mestrado em Educação Ambiental (Remea) ${ }^{7}$.

Em seguida, realizamos um inventário dos volumes e edições disponíveis entre 20142018, a partir de visita ao sítio eletrônico de cada periódico. Alguns possuem volumes especiais, (veiculando publicações de trabalhos apresentados em eventos científicos no campo da EA, por exemplo) que não foram incorporados. Também não foram incorporados relatos de experiência. Ao todo, consideramos quinze volumes, 49 edições e 639 relatos de pesquisa.

A partir da seleção dessas pesquisas, optamos por dois conjuntos de descritores de análise. Um deles, ligado às características dos periódicos, sendo composto por: a) ano de

\footnotetext{
${ }^{4}$ PEA. Disponível em: www.periodicos.rc.biblioteca.unesp.br/index.php/pesquisa. Acesso em: 10 nov. 2018.

${ }^{5}$ RevBEA. Disponível em: http://www.sbecotur.org.br/revbea/index.php/revbea. Acesso em: 10 nov. 2018.

${ }^{6}$ Ambiente \& Educação. Disponível em: https://periodicos.furg.br/ambeduc. Acesso em: 10 nov. 2018.

${ }^{7}$ Remea. Disponível em: https://periodicos.furg.br/remea. Acesso em: 10 nov. 2018.
} 
início; b) número de volumes publicados; c) instituições responsáveis e d) indicadores de internacionalização da produção. Especificamente sobre esse indicador, consideramos a publicação de artigos em outras línguas, o número de membros estrangeiros que compõem a comissão científica, a quantidade de indexadores internacionais e o número de acessos à página eletrônica dos periódicos por pessoas de outros países, quando disponível.

Para o segundo conjunto, consideramos descritores referentes aos relatos de pesquisa analisados, sendo eles:

a) Ano, volume e número de publicação

b) Contexto educacional - divide-se em Contexto escolar, Contexto não escolar, Abordagem genérica do contexto educacional (CARVALHO et al., 2016);

c) Tema de estudo - especifica a temática principal que foi objeto de investigação, tais como: Concepções/Representações/Percepções e Processos Cognitivos; Currículos, Programas e Projetos; Fundamentos em EA; Políticas Públicas em EA; Processos e Métodos de Ensino e de Aprendizagem; Recursos Didáticos; Trabalho e Formação de Professores/Agentes de EA, entre outros (CARVALHO et al., 2016).

Os descritores b e c foram assumidos a partir do Projeto EArte e o descritivo completo pode ser encontrado no sítio eletrônico do projeto ${ }^{8}$.

Por fim, realizamos leitura do título, resumo, palavras-chave e, quando necessário, dos trabalhos completos. Os dados de classificação foram compilados em planilhas, a fim de sistematizar, organizar e possibilitar a análise deles.

\section{Características dos periódicos analisados}

No Brasil, o Programa de Pós-Graduação em Educação Ambiental da Furg foi o responsável pela organização e publicação dos periódicos mais antigos, que possuem como foco a divulgação da pesquisa em EA: a revista Ambiente \& Educação, em 1996, na versão impressa e, também, a Revista Eletrônica do Mestrado em Educação Ambiental (Remea) em 1999. O Quadro 1 apresenta informações pertinentes a essas publicações.

\begin{tabular}{|l|c|l|c|}
\hline \multicolumn{1}{|c|}{ Nome } & $\begin{array}{l}\text { Ano de } \\
\text { criação }\end{array}$ & \multicolumn{1}{|c|}{ Instituições responsáveis } & $\begin{array}{l}\text { Quantidade } \\
\text { de Volumes }\end{array}$ \\
\hline $\begin{array}{l}\text { Ambiente \& Educação: revista } \\
\text { de Educação Ambiental }\end{array}$ & 1994 & $\begin{array}{l}\text { Programa de Pós-Graduação em Educação } \\
\text { Ambiental da FURG }\end{array}$ & 23 v. \\
\hline $\begin{array}{l}\text { Revista Eletrônica do do } \\
\text { Mestrado em Educação } \\
\text { Ambiental (Remea) }\end{array}$ & 1999 & $\begin{array}{l}\text { Programa de Pós-Graduação em Educação } \\
\text { Ambiental da FURG }\end{array}$ & $35 \mathrm{v}$. \\
\hline $\begin{array}{l}\text { Revista Brasileira de Educação } \\
\text { Ambiental (RevBEA) }\end{array}$ & 2004 & Rede Brasileira de Educação Ambiental (Rebea) & $13 \mathrm{v}$. \\
\hline $\begin{array}{l}\text { Pesquisa em Educação } \\
\text { Ambiental (PEA) }\end{array}$ & 2006 & $\begin{array}{l}\text { - UFSCar (Programas de Pós-Graduação em } \\
\text { em Educação); } \\
\text { - UNESP, Rio Claro (Grupo de Pesquisa “A } \\
\text { temática ambiental e o processo educativo" do } \\
\text { Programa de Pós-Graduação em Educação) }\end{array}$ & 13 v. \\
\hline
\end{tabular}

${ }^{8}$ Para maiores informações sobre os descritores elaborados pelos pesquisadores do Projeto EArte, acesse: http://www.earte.net/?page=projeto-descritores. 


\begin{tabular}{|l|l|l|l|}
\hline & $\begin{array}{l}\text { USP, Ribeirão Preto, (Laboratório } \\
\text { Interdisciplinar de Formação do Educador-LAIFE } \\
\text { da Faculdade de Filosofia, Ciências e Letras) }\end{array}$ & \\
\hline Observação: a quantidade de volumes apresentada refere-se do ano de início até 2018. \\
\hline
\end{tabular}

Quadro 1 - Informações sobre os periódicos analisados Fonte: dados compilados pelas autoras

O periódico Ambiente \& Educação tem como foco e escopo "intensificar as discussões sobre a formação de educadores(as) ambientais pesquisadores, capazes de contribuir para a produção de conhecimento e a criação de alternativas no campo da EA"9. Em 2006, passou a disponibilizar artigos no formato digital e sua periodicidade é semestral.

Já a Remea elenca como objetivos "aprofundar por meio da publicação de artigos a compreensão crítica da atual crise sócio-ecológica no Brasil e no mundo; difundir pesquisas na área da EA, possibilitando o leitor identificar problemas e propor soluções, dentro de sua área de conhecimento e atuação"

Em 2004 foi criada a Revista Brasileira de Educação Ambiental (RevBEA), a qual divulga relatos de pesquisa e de experiência. Segundo informações de sua página eletrônica ${ }^{11}$, busca "o acolhimento dos textos produzidos no campo da Educação Ambiental, independentemente da sua natureza, postura que se justifica em função do vasto e heterogêneo perfil dos protagonistas que atuam nessa área no Brasil".

A revista Pesquisa em Educação Ambiental (PEA) nasceu a partir da articulação de pesquisadores da Universidade Federal de São Carlos (Ufscar), da Universidade Estadual Paulista (Unesp), de Rio Claro, e da Universidade de São Paulo (USP), de Ribeirão Preto, vinculados à comissão organizadora do Encontro Pesquisa em Educação Ambiental (EPEA); sua periodicidade é semestral (até o ano de realização deste estudo, 2018) e tem como foco a "publicação destinada à divulgação de trabalhos de pesquisa em Educação Ambiental, com a missão de contribuir para a consolidação e fortalecimento deste campo"12.

Considerando a expansão e a divulgação de pesquisas publicadas nos periódicos investigados, bem como a importância de possibilitar o acesso e difusão a pesquisadores e estudantes de outros países, analisamos aspectos que podem ser indícios de um processo de internacionalização desses periódicos.

Uma dessas iniciativas se refere à publicação de artigos em outras línguas, denominada por Packer (2011) de multilinguismo. Conforme o autor, os periódicos brasileiros publicam, majoritariamente, artigos em português, embora a proporção entre artigos em português e inglês varie conforme as áreas do conhecimento.

Entre 2014-2018, a Remea publicou três artigos na língua espanhola, representando $1 \%$ da produção analisada. Na revista Ambiente \& Educação foram publicados dois artigos (2\%), sendo um na língua inglesa e outro em espanhol. Já no periódico RevBEA, foram publicados cinco artigos, quatro na língua espanhola e um em inglês, representando $2 \%$ dos estudos.

\footnotetext{
${ }^{9}$ Informações disponíveis no sítio eletrônico do periódico: https://periodicos.furg.br/ambeduc/ index. Acesso em: 06/01/2019.

${ }^{10}$ Informações disponíveis no sítio eletrônico do periódico: https://periodicos.furg.br/remea. Acesso em: 06/01/2019.

${ }^{11}$ Informações disponíveis no sítio eletrônico do periódico: http://www.sbecotur.org.br/revbea/index.php/revbea. Acesso em: 06/01/2019.

${ }^{12}$ Informações disponíveis no sítio eletrônico do periódico: https://www.periodicos.rc.biblioteca.unesp.br/index.php/pesquisa/about. Acesso em: 06/01/2019.
} 
Na revista PEA foram publicados dezesseis artigos em outras línguas (nove textos em inglês e sete em espanhol), totalizando $15 \%$ das publicações. Também, indicamos a presença de um número especial da revista, no ano 2018, contendo oito artigos em inglês. Além disso, a presença de artigos em língua estrangeira na PEA pode estar relacionada com a publicação elaborada por conferencistas internacionais, a partir de suas exposições em edições do Encontro Pesquisa em Educação Ambiental (EPEA).

Cabe destacar que essas informações apresentadas, concernentes às características dos periódicos analisados, foram coletadas nos sítios eletrônicos e abrangem até o ano de 2018 (Tabela 1).

Tabela 1 - Indicadores de internacionalização analisados nos periódicos Remea, Ambiente \& Educação, RevBEA e PEA: período de 2014-2018.

\begin{tabular}{lcccc}
\hline \multicolumn{1}{c}{ Indicadores / Periódicos } & Remea & $\begin{array}{c}\text { Ambiente \& } \\
\text { Educação }\end{array}$ & RevBEA & PEA \\
\hline Artigos publicados em outras línguas & $\begin{array}{c}1 \% \\
\text { (total=217) }\end{array}$ & $\begin{array}{c}2 \% \\
\text { (total=99) }\end{array}$ & $\begin{array}{c}2 \% \\
\text { (total=223) }\end{array}$ & $\begin{array}{c}15 \% \\
\text { (total=100) }\end{array}$ \\
$\begin{array}{l}\text { Número de membros estrangeiros } \\
\text { integrantes da Comissão Científica }\end{array}$ & $\begin{array}{c}2 \% \\
\text { (Total=44) }\end{array}$ & $\begin{array}{c}4 \% \\
\text { (Total=109) }\end{array}$ & - & $\begin{array}{c}19 \% \\
\text { (Total=36) }\end{array}$ \\
Indexadores internacionais & 3 & 11 & 1 & 7 \\
\hline
\end{tabular}

Nota: com exceção do número de artigos publicados em outras línguas, os demais foram considerados a partir de quantificação realizada em janeiro de 2019, por meio dos sítios eletrônicos dos periódicos.

Fonte: dados sistematizados pelas autoras

Em relação aos membros estrangeiros que constituem as comissões científicas das revistas, observamos que na Remea há um, dentre 44 membros $(2 \%)$, pertencente à uma universidade uruguaia. No sítio eletrônico da Ambiente \& Educação constam 109 membros dos quais cinco (4\%) são estrangeiros, sendo quatro de universidades espanholas e um da Alemanha. A PEA possui 36 pesquisadores que constituem a comissão científica, dos quais sete $(15 \%)$ são membros estrangeiros do conselho editorial, pertencentes a universidades do México, Espanha, Portugal, África do Sul, Reino Unido, Canadá e Austrália.

Em relação aos indexadores internacionais, Carvalho e Sasseron (2014) alertam para a existência de tensões presentes no processo de internacionalização da produção de conhecimentos no campo educacional nacional, em especial nos periódicos científicos. Entretanto, de acordo com Packer (2011, p. 31), estar indexado concede aos periódicos visibilidade, e é de suma importância para que os mesmos - e, consequentemente, para os trabalhos por eles divulgados - sejam "habilitados a participar dos processos de recuperação e avaliação de informação científica", de maneira que tais indexadores são uma das formas de divulgação das publicações dos periódicos, facilitando o acesso por parte de pesquisadores de outros países.

A Remea está em três indexadores, sendo dois ibero-americanos, com criação na Espanha e Portugal. Já a Ambiente \& Educação encontra-se alocada em onze indexadores, sendo dois da América Latina, um da América do Norte e oito europeus. Por sua vez, a RevBEA está em um indexador europeu. Por fim, a PEA está alocada em sete indexadores, dos quais três são norte-americanos, um africano e três europeus.

Outro indicativo de internacionalização pode ser os acessos às páginas eletrônicas das revistas por estrangeiros. Apenas dois dos periódicos analisados disponibilizavam essa 
informação, conforme busca realizada em 04 de janeiro de 2019. No caso da revista Ambiente \& Educação, a informação indicava que $10,3 \%$ dos acessos foram realizados por pessoas de outros países. Já na revista PEA, 10,5\% dos acessos decorrem de 54 países diferentes. Cabe destacar que o acesso a essas revistas é aberto e, nesse sentido, segundo Packer (2011), tal acesso é fundamentado ao conceber-se o conhecimento científico como um bem público e no fato de as pesquisas serem financiadas por recursos financeiros públicos, em sua maior parte.

Contudo, indicamos a necessidade de estudos mais sistemáticos sobre esses indicativos apresentados.

\section{Panorama dos relatos de pesquisa em EA analisados}

A distribuição dos relatos de pesquisa conforme ano de publicação, no período 20142018, pode ser vista na Figura 1. Há uma acentuação nas publicações, entre os anos de 2016 e 2017, o que pode estar relacionado à quantidade de números regulares. A esse respeito, pontuamos que a RevBEA, em 2014, publicava três números/ano, e em 2015, passou a publicar quatro edições anuais; já a Remea, a partir do ano de 2017, passou a publicar três números regulares. Outro fator de influência seria o número de trabalhos recebidos e aceitos pelas revistas, assim como a regularidade de artigos a serem publicados.

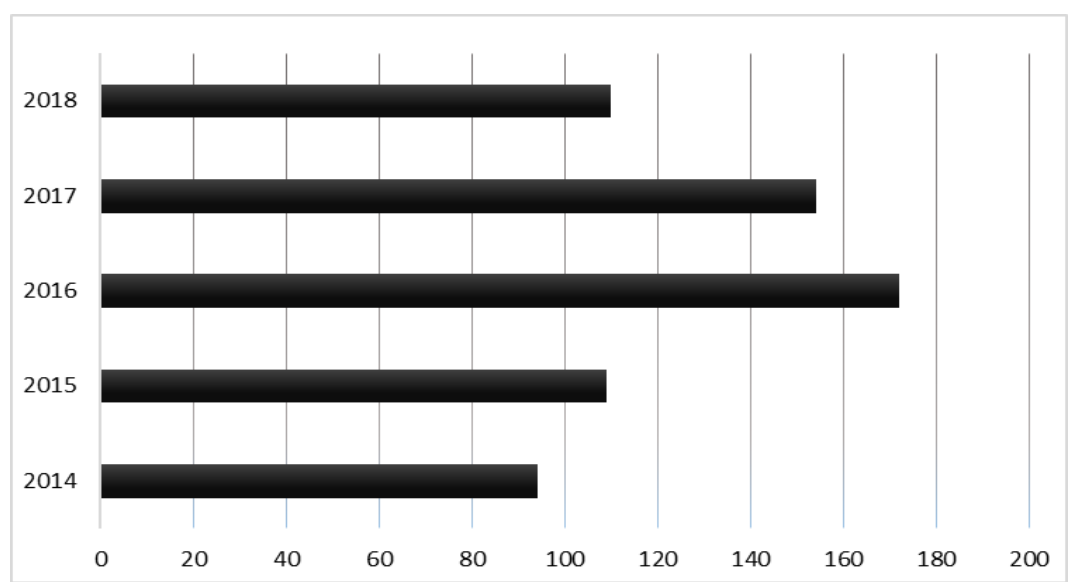

Figura 1 - Distribuição temporal dos relatos de pesquisa em EA veiculados pelos periódicos científicos Remea, RevBEA, PEA e Ambiente \& Educação: período de 2014-2018

Fonte: dados sistematizados pelas autoras

Com relação ao contexto educacional, há predominância do contexto escolar em relação ao não escolar, tanto em relação ao total de publicações, quanto à quantidade de artigos por revista. Dos 639 artigos analisados, $331(51,7 \%)$ direcionam o trabalho a um determinado nível de ensino dentre diferentes níveis escolares, compreendendo desde a educação infantil ao ensino superior.

O contexto não escolar corresponde a 169 (26,4\%) dos artigos. Constatamos que, em $145(22,6 \%)$ dos relatos de pesquisa, não foi possível identificar uma preocupação com discussões específicas sobre o contexto educacional escolar ou não escolar, realizando, assim, uma abordagem genérica. A Figura 2 exprime os resultados. 


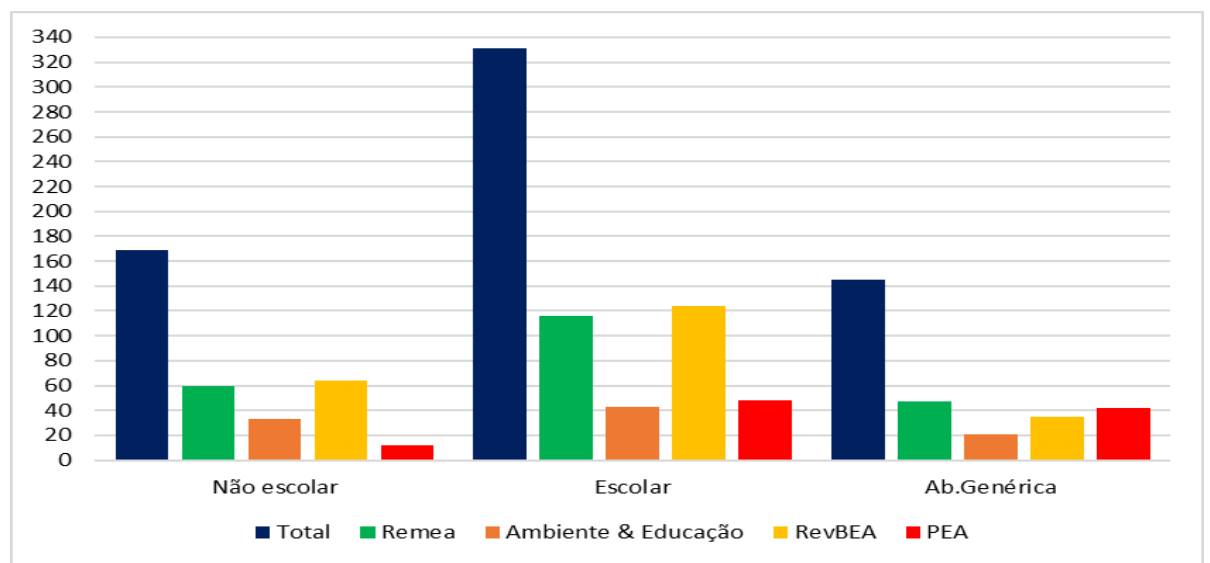

Figura 2 - Número de relatos de pesquisa em EA veiculados pelos periódicos científicos da Remea, RevBEA, PEA e Ambiente \& Educação no período de 2014-2018, conforme contexto educacional Fonte: dados sistematizados pelas autoras

Apesar das especificidades relativas à produção conforme periódico, identificamos a predominância do contexto educacional escolar nos trabalhos, elemento que foi relatado por Carvalho (2009) como uma característica da produção em EA há doze anos.

Há quatro temas de estudo que aglutinam pouco mais de $70 \%$ da produção analisada (Tabela 2), são eles: Concepções/ Representações/Percepções e Processos Cognitivos (31\%); Fundamentos em EA (14,4\%); Processos e Métodos de Ensino e de Aprendizagem $(14,2 \%)$ e Currículos, Programas e Projetos (12,5\%).

Tabela 2 - Distribuição dos relatos de pesquisa em EA veiculados pelos periódicos científicos Remea, RevBEA, PEA e Ambiente \& Educação, no período de 2014-2018, conforme tema de estudo privilegiado

\begin{tabular}{ccc}
\hline Temas de Estudo & $\begin{array}{c}\text { Número de } \\
\text { classificações }\end{array}$ & \% \\
\hline Funcepções/Representações/Percepções e Processos Cognitivos & 198 & 31,0 \\
Fundamentos em EA & 92 & 14,4 \\
Processos e Métodos de Ensino e de Aprendizagem & 91 & 14,2 \\
Currículos, Programas e Projetos & 80 & 12,5 \\
Trabalho e Formação de Professores/Agentes de EA & 49 & 7,7 \\
Políticas Públicas em EA & 29 & 4,5 \\
Recursos Didáticos & 22 & 3,4 \\
Outro & 83 & 19,7 \\
Total & $\mathbf{6 8 6}$ & $\mathbf{1 0 7 , 4}$ \\
\hline
\end{tabular}

Nota: o total de classificações para a coluna número de classificações ultrapassa os 639 artigos, pois 47 trabalhos foram classificados em mais de um tema de estudo. Já as porcentagens foram calculadas sobre o total de artigos ultrapassando, portanto, $100 \%$. 
Os trabalhos classificados em Concepções/ Representações/Percepções e Processos Cognitivos compõem maior parte da amostra (31\%), totalizando 198 relatos. Podemos distinguir dois subconjuntos: 139 estudos $(21,8 \%)$ identificam as visões, concepções, percepções, sentidos, significados e/ou conhecimentos prévios de um ou mais aspectos relacionados à temática ambiental em alunos, público visitante de espaços não formais ou ainda, em população de um bairro, cidade ou local; podendo articular ou não tais características com o perfil socioeconômico do grupo envolvido, por exemplo (CARVALHO et al., 2016). Já 59 trabalhos $(9,2 \%)$ tem como público-alvo da investigação professores, educadores ambientais ou outros profissionais que atuem em EA, podendo, ainda, realizar um diagnóstico da prática dos mesmos.

Ao relacionarmos esse tema de estudo com o contexto educacional, a maior parte dos trabalhos envolveram públicos ligados ao contexto escolar (57 de 59 estudos envolvendo profissionais e/ou professores, perfazendo 97\%; e 85 de 139 estudos cujo público envolveu alunos e/ou aprendizes, totalizando cerca de $41 \%$ ).

O predomínio de trabalhos de pesquisa no campo da EA, que lidam com características e concepções de indivíduos, já foi relatado por diversos estudos. Citamos a pesquisa de Pato, Sá e Catalão (2009), que buscou analisar as pesquisas apresentadas na área de Educação Ambiental (GT-22) das reuniões ocorridas entre 2003-2007 da Associação Nacional de Pós-Graduação e Pesquisa em Educação (ANPEd), e de Rink (2009), ao investigar os artigos publicados nos Anais dos Encontros Pesquisa em Educação Ambiental (EPEA) (2001, -2007). Carvalho e Schimidt (2008, p. 168, 169) indicam que trabalhos com essa ênfase temática mostram preocupação com os "sentidos da EA", e que a grande quantidade desses estudos pode estar, de certo modo, ligada à busca por "investigar certos conceitos ambientais para grupos específicos, uma estratégia de pesquisa que se tornou muito popular entre os trabalhos dos pesquisadores mais jovens da EA".

O segundo tema de estudo mais presente foi o de Fundamentos de EA (FundEA) $(14,4 \%)$. São trabalhos que discutem fundamentos filosóficos, históricos, epistemológicos e/ou metodológicos em EA. Para Kawasaki e Carvalho (2009, p. 154), tais estudos, ainda que se refiram a vivências concretas, "buscam construir modelos explicativos de maior alcance, construindo diálogos e interlocuções com autores e campos disciplinares diversos". Ao tecer uma análise da produção dos eventos EPEA e Reuniões da ANPEd, os autores apontaram para o predomínio de pesquisas de natureza empírica e que investigam práticas educativas; contudo, também ressaltaram o número crescente de trabalhos de natureza teórica e relacionados aos fundamentos teóricos e metodológicos da EA, principalmente em periódicos; destacando que tal fenômeno pode ser evidenciado nas publicações dos cinco números iniciais da Revista de Pesquisa em Educação Ambiental (2006-2008) (KAWASAKI; CARVALHO, 2009).

O terceiro tema de estudo mais presente nos relatos de pesquisa, com 91 trabalhos $(14,2 \%)$ busca discutir e analisar o que denominamos de Processos e Métodos de Ensino e de Aprendizagem em EA (PMEA). São pesquisas que tratam sobre a "aplicação ou da avaliação de processos, métodos, estratégias e técnicas no ensino-aprendizagem de EA, de forma isolada ou comparativa com outros conteúdos, métodos, estratégias e técnicas" (CARVALHO et al., 2016, s.p), ou ainda, propõem estratégias alternativas para a realização de atividades em EA, que descreveram e/ou avaliaram processos de ensino-aprendizagem em EA.

Relatos de pesquisa cujo tema de estudo privilegiado foi Currículos, Programas $e$ Projetos (CPP) compõem 12,5\% da produção (oitenta documentos). Segundo Carvalho et al. (2016), o tema compreende estudos que propõem, analisam e avaliam programas ou projetos em EA, seja numa série específica, numa disciplina ou até mesmo num curso como um todo. 
Para Kawasaki e Carvalho (2009, p. 146), apesar de estudos ligados ao contexto escolar predominarem em relação aos não escolares, "tanto em um contexto quanto em outro, as práticas educativas e os projetos e programas são as temáticas predominantes", ou seja, pesquisas que lidam com currículos, projetos e práticas educativas são majoritárias, corroborando com as tendências apontadas por esta investigação. Tal característica também foi encontrada na produção aqui analisada. Todavia, a distribuição desses temas, em cada um dos periódicos investigados, não é homogênea (Figura 3). 


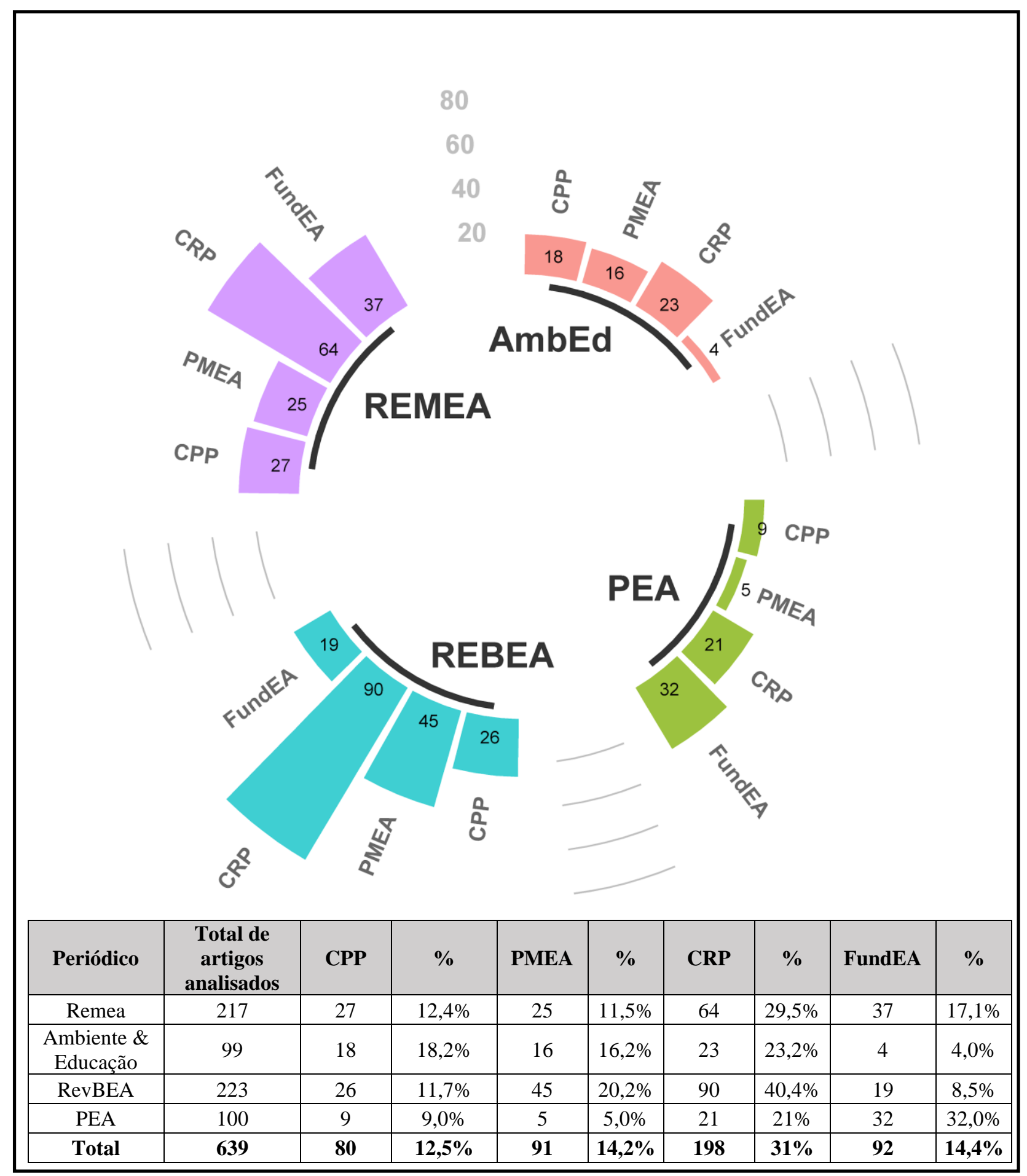

Figura 3 - Distribuição dos Temas de Estudo quantitativamente mais expressivos nos relatos de pesquisa em EA pelos periódicos Remea, RevBEA, PEA \& Ambiente \& Educação, no período de 2014-2018

Fonte: dados sistematizados pelas autoras

Legenda: Currículos, Programas e Projetos (CPP); Concepções/Representações/ Percepções e Processos Cognitivos (CRP); Processos e Métodos de Ensino e de Aprendizagem (PMEA); Fundamentos em EA (FundEA). Adaptados de Carvalho et al. (2016). 
Notamos que o periódico PEA possui 32\% de trabalhos classificados em Fundamentos de $E A$, enquanto a RevBEA possui maior quantidade de artigos ligados a estudos sobre concepções e representações de indivíduos, por exemplo. Tais resultados podem estar associados às características de cada revista, a exemplo da PEA que publica artigos elaborados pelos palestrantes associados à discussão no EPEA, como já mencionado, assim como análises dos trabalhos apresentados elaborados pelos mediadores dos diversos grupos de trabalhos (GTs) do evento. Esses estudos se tornam expressivos, quantitativamente, na produção do periódico, tendo em vista a publicação de dois números regulares por ano.

Observamos, também, que o tema Concepções/Representações/Percepções $e$ Processos Cognitivos (CRP) detém o maior número de trabalhos e possui representatividade regular em todas as revistas selecionadas (Remea - 29,5\%, Ambiente \& Educação - 23,2\%, RevBEA - 40,4\% e PEA - 21\%. Em menor proporção, o tema Currículos, Programas $e$ Projetos $(C P P)(12,5 \%)$ está presente em dezoito artigos $(18,2 \%)$ na Ambiente \& Educação e em nove trabalhos $(9 \%)$ na PEA.

Consideramos que tanto a distribuição dos temas de estudo, quanto as particularidades de cada revista sugerem possibilidades para delimitação de um perfil que possa vir a indicar as contribuições das mesmas para o campo de pesquisa em EA, no Brasil; nesse sentido, entendemos ser necessário o desenvolvimento de estudos mais aprofundados a esse respeito.

Nos chamou atenção o pequeno número de trabalhos classificados como Políticas Públicas em EA (29 estudos, 4,5\% da amostra). Segundo Carvalho et al. (2016), trata-se de uma importante lacuna a ser superada na pesquisa em EA e os autores apontam para a carência de pesquisas que se debruçam sobre a análise e/ou avaliação de programas, diretrizes e ações voltadas para o público em geral. Entretanto, resultados similares também foram obtidos por Fernandes, Megid Neto e Fracalanza (2005), a respeito de estudos que tenham como foco Políticas Públicas nas pesquisas em Educação em Ciências, mostrando que essa lacuna não é característica específica da produção em EA.

Há outros temas de estudo com percentuais reduzidos (menos de 4\%) no cômputo da amostra considerada. É o caso de Recursos Didáticos (3,4\%); Organização governamental (2,8\%); Organização da instituição escolar (1,3\%); Movimentos Sociais e Movimentos Ambientalistas $(1,3 \%)$ e Comunicação $(1,1 \%)$ e Organização não governamental $(0,2 \%)$. Entretanto, concordamos com Carvalho e Schmidt (2008) ao observarem que uma menor expressão quantitativa de uma ou mais temáticas não significa que sejam menos relevantes para o campo da EA, ou que não há interesse por elas. Conforme Rink (2009), há necessidade de manter tais temas em destaque, seja pela relevância deles no campo da EA ou para alertar sobre a importância de desenvolver e divulgar pesquisas que lidem mais intensamente com os mesmos.

\section{Considerações finais}

Neste artigo, nos propusemos a analisar as tendências presentes nos relatos de pesquisa publicados em quatro periódicos brasileiros - Remea, Ambiente \& Educação, RevBEA e PEA - que se dedicam à divulgação das pesquisas em Educação Ambiental. No período de 2014 a 2018, consideramos no estudo 639 relatos de pesquisa. Observamos que as primeiras revistas do campo da EA, criadas no Brasil, são do ano 1990, a Ambiente \& Educação e a Remea, ambas sob responsabilidade do Programa de Pós-Graduação em Educação Ambiental da Universidade Federal do Rio Grande do Sul. Posteriormente, foi criada a RevBEA, pela Rede Brasileira de Educação Ambiental, em 2004, e, mais recentemente, em 2006, a Pesquisa em Educação Ambiental (PEA), sob responsabilidade de 
grupos de pesquisadores da Unesp de Rio Claro/SP, USP de Ribeirão Preto/SP, e Ufscar de São Carlos/SP.

Ao analisarmos alguns indicadores de internacionalização, observamos que há relatos de pesquisa em línguas estrangeiras (inglês e espanhol), e que as revistas também possuem membros estrangeiros na comissão científica. Além disso, os periódicos estão alocados em indexadores internacionais, em outros continentes.

Com relação à distribuição da publicação por ano, há uma acentuação nas publicações entre os anos de 2016 e 2017, podendo ser atribuída a quantidade de números regulares publicados, que aumentou em dois periódicos; sendo necessário considerar se houve aumento na quantidade de relatos de pesquisa enviados para análise e aceitos para publicação.

O contexto escolar é o contexto educacional predominante nos trabalhos analisados, correspondendo a $331(51,7 \%)$ dos artigos; seguido pelo contexto não escolar, com 169 estudos $(26,4 \%)$, e a abordagem genérica, com 145 (22,6\%) dos relatos de pesquisa. Isso nos indica que as investigações desenvolvidas no campo da EA, nos últimos cinco anos (até 2018), ainda privilegiam o contexto escolar, seja na produção veiculada por periódicos no campo da EA ou como contexto de estudo para o desenvolvimento de teses e dissertações.

Quanto aos temas de estudo, artigos que identificam e discutem concepções, representações, percepções sobre elementos ligados à temática ambiental, compõem a maior parte da amostra analisada, correspondendo a $31 \%$ dos trabalhos. O segundo tema de estudo mais presente envolve artigos que problematizam e discutem as relações entre Educação, EA e Sociedade, assim como outras questões referentes ao contexto educacional escolar ou não escolar, relacionados aos Fundamentos da EA, com 14,4\% dos documentos.

Por outro lado, temas de estudos que descrevem, avaliam ou realizam diagnósticos ou estudos de características de instituições escolares, não escolares ou não formais de ensino, e organizações ligadas à governos (nas esferas municipal, estadual ou federal) estão pouco presentes e totalizam 1,3\% dos artigos, bem como pesquisas que tem como foco explorar, discutir ou caracterizar o movimento ambientalista e movimentos sociais, que representa, também, apenas $1,3 \%$ dos trabalhos. Indicando, ainda, uma certa carência no campo de pesquisa em EA referente a investigações que explorem essas temáticas.

A partir das reflexões e sistematizações neste estudo, esperamos contribuir para a discussão sobre a produção acadêmica veiculada pelos periódicos, em específico sobre os tipos e enfoques de pesquisa privilegiados pelo campo da EA.

\section{Agradecimentos}

Agradecemos a Leandro Giacobelli Cosmo pelo auxílio na construção da Figura 3 deste texto.

\section{Referências}

AMBIENTE \& EDUCAÇÃO. Disponível em: https://periodicos.furg.br/ambeduc. Acesso em: 10 nov. 2018.

CARVALHO, I. C. M.; SCHMIDT, L. A pesquisa em Educação Ambiental: uma análise dos trabalhos apresentados na ANPED, ANPPAS e EPEA de 2001 a 2006. Pesquisa em Educação Ambiental, Rio Claro, v. 3, n. 2, p.147-174, jul/dez, 2008. https://doi.org/10.18675/2177-580X.vol3.n2.p147-174.

Acesso em: 10 jan. 2019.

CARVAlHO, L. M. de. Pesquisa Em Educação Ambiental No Brasil: Um Campo Em Construção? 2015, 455 f. Tese (Livre-Docência em Educação Ambiental) - Universidade Estadual Paulista 'Júlio de Mesquita Filho", Rio Claro, 2015. 
CARVALHO, L. M. et al. Relatório do Projeto A Educação Ambiental no Brasil: análise da produção acadêmica (dissertações e teses). Rio Claro: UNESP/UNICAMP/USP/UFSCar, 2016.

CARVALHO, M. P.; SASSERON, L. H. The internationalization of Brazilian education journals: tensions of an ongoing process. Educação e Pesquisa, São Paulo, v.40, n.4, p.869-876, out/dez, 2014. https://dx.doi.org/10.1590/S1517-970220144004001. Acesso em: 10 jan. 2019.

CAVALARI, R. M. F.; SANTANA, L. C.; CARVALHO, L. M. Concepções de educação e Educação Ambiental nos trabalhos do I EPEA. Pesquisa em Educação Ambiental, Rio Claro, v. 1, n. 1, p.141173, jul/dez, 2006. https://doi.org/10.18675/2177-580X.vol1.n1.p141-173. Acesso em: 10 jan. 2019.

DIAS, G. M. A dimensão valorativa da educação ambiental na formação continuada de professores apresentada em teses e dissertações brasileiras. 2012, 146f. Dissertação (Mestrado em Educação) Universidade Estadual Paulista “Júlio de Mesquita Filho", Rio Claro, 2012.

FERNANDES, R.C. A.; MEGID NETO, J; FRACALANZA, H. O que sabemos sobre a pesquisa em Educação em Ciências no Brasil (1972-2004). In: ENCONTRO NACIONAL DE PESQUISA EM EDUCAÇÃO EM CIÊNCIAS, 5, 2005, Bauru. Anais... Bauru: Abrapec, 2005. p. 1-10. Disponível em: http://www.nutes.ufrj.br/abrapec/venpec/conteudo/artigos/3/pdf/p648.pdf. Acesso em: 10 jan. 2019.

KAWASAKI, C. S.; CARVALHO, L. M. Tendências da pesquisa em Educação Ambiental. Educação em Revista, Belo Horizonte, v. 25, n. 3, p. 143-157, dez, 2009. https://doi.org/10.1590/S010246982009000300008. Acesso em: 10 jan. 2019.

KREUZ, A. M. Estado da arte das produções na Revista Brasileira de Educação Ambiental de 2010 a 2016. 2018, 165f. Dissertação (Mestrado em Geografia) - Universidade Estadual do Oeste do Paraná, Francisco Beltrão, 2018.

MEGID NETO, J. Educação Ambiental como campo de conhecimento: a contribuição das pesquisas acadêmicas para sua consolidação no Brasil. In: Pesquisa em Educação Ambiental, Rio Claro, v. 4, n. 2, p. 95-110, jul/dez, 2009. https://doi.org/10.18675/2177-580X.vol4.n2.p95-110. Acesso em: 10 jan. 2019.

NOGUEIRA, M. L. S. L. S. Práticas interdisciplinares em educação ambiental na educação básica: o que nos revelam as pesquisas acadêmicas brasileiras. 2016. 336f. Tese (Doutorado em Educação) Universidade Estadual de Campinas, Campinas, 2016.

PACKER, A. L. Os periódicos brasileiros e a comunicação da pesquisa nacional. In: Revista USP, São Paulo, n. 89, p. 26-61, mar/mai, 2011. https://doi.org/10.11606/issn.2316-9036.v0i89p26-61. Acesso em: 10 jan. 2019.

PATO, C.; SÁ, L. M.; CATALÃO, V. L. Mapeamento de tendências na produção acadêmica sobre Educação Ambiental. In: Educação em Revista, Belo Horizonte, v. 25, n.3, p. 213-233, dez, 2009. https://doi.org/10.1590/S0102-46982009000300011. Acesso em: 10 jan. 2019.

PESQUISA EM EDUCAÇÃO AMBIENTAL (PEA). Disponível em: www.periodicos.rc.biblioteca.unesp.br/index.php/pesquisa/index. Acesso em: 10 nov. 2018.

REVISTA ELETRÔNICA DO MESTRADO EM EDUCAÇÃO AMBIENTAL (REMEA). Disponível em: https://periodicos.furg.br/remea. Acesso em: 10 nov. 2018.

REVISTA BRASILEIRA DE EDUCAÇÃO AMBIENTAL (RevBEA).

Disponível em: http://www.sbecotur.org.br/revbea/index.php/revbea. Acesso em: 10 nov. 2018. 
RINK, J. Análise da produção acadêmica apresentada nos Encontros de Pesquisa em Educação Ambiental (EPEA). 2009. 217 f. Dissertação (Mestrado em Educação) - Universidade Estadual de Campinas, Campinas, 2009.

SANTOS, L. M. F.; MARTINS, I. Mapeamento do campo a partir de publicações em periódicos das áreas de educação ambiental, educação em ciências e educação no período de 1999 a 2006. In: ENCONTRO NACIONAL DE PESQUISA EM EDUCAÇÃ̃O EM CIÊNCIAS, 6, 2007, Florianópolis. Anais... Florianópolis: Abrapec, 2007, p.1-11. Disponível em: http://fep.if.usp.br/ profis/arquivos/vienpec/CR2/p590.pdf. Acesso em: 10 jan. 2019.

SATO, M.; SANTOS, J. E. Tendências nas Pesquisas em Educação Ambiental. In: NOAL, F. O.; BARCELOS, V. H. L. (Orgs.). Educação Ambiental e Cidadania: Cenários Brasileiros. Santa Cruz do Sul: EDUNISC, 2003. p. 253-283. 